\title{
OPTIMUM SELECTION OF WEDM CONDITIONS FOR CK45 STEEL
}

\author{
T. A. El-Taweel, A. H. Youssef and A. M. Hewidy \\ Mechanical Design and Production Engineering Department \\ Faculty of Engineering, Minoufiya University, Shebin El-Kom, Egypt
}

\begin{abstract}
The present paper presents a study of the optimum selection of wire electric discharge machining conditions for CK45 steel. Response surface methodology (RSM) has been utilized to analyze and determine the optimal parameters setting in the WEDM for CK45 steel. The process performance criteria such as material removal rate, tool wear rate, and surface roughness were evaluated. Feeding speed, duty factor, water pressure, wire tension and wire speed, have been considered the main factors affecting WEDM performance. RSM was employed for developing experimental models. Analysis of variance test has also been carried out to check the adequacy of the developed models. The results of the present work reveal that the feeding speed and duty factor are the most vital factors controlling the metal removal rate. Water pressure has been found to have a sensible effect of MRR especially at a higher feeding speed. Further, the minimum tool wear rate has been obtained at the parametric combination of low feeding speed and low duty factor. In general, it has been found that the increase of water pressure, wire tension and wire speed decreases tool wear. It has also been clarified that the increase of wire tension and wire speed leads to a relatively insignificant change in surface quality.

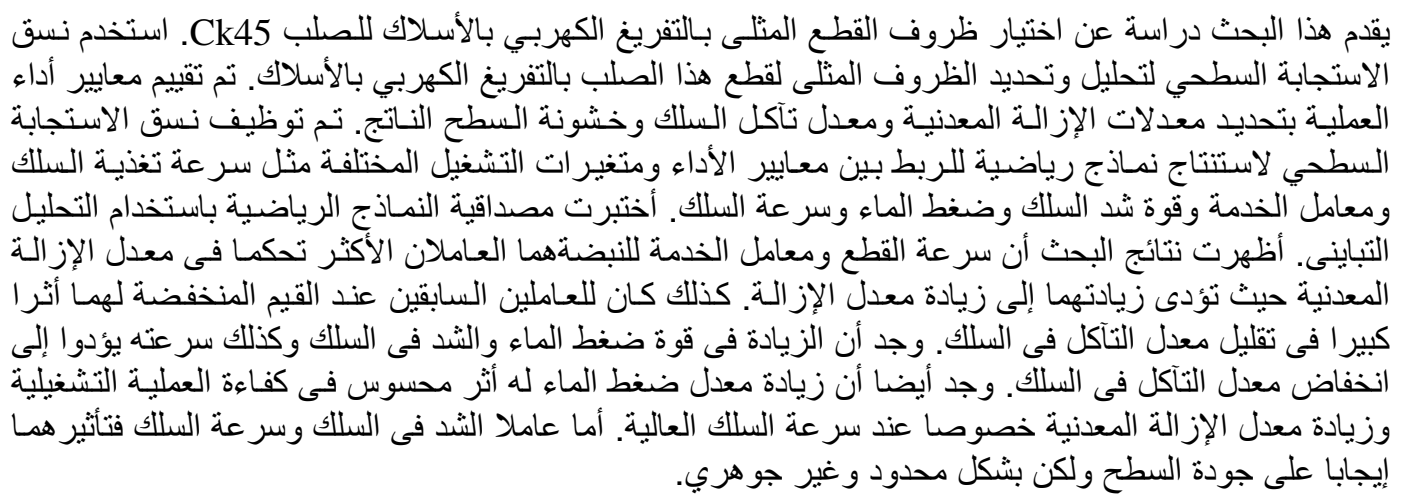

Keywords: WEDM, Material Removal Rate, Tool Wear Rate, Surface Roughness, Response Surface Methodology and Optimization.

\section{INTRODUCTION}

Electrical discharge machining (EDM) is one of the non traditional machining processes which has been widely used to produce dies and molds. It is also used for finishing parts for aerospace and automotive industry and surgical components [1]. This technique developed in the late 1940s [2] where the process is based on removing material from a part by means of a series of repeated electrical discharges between tool called the electrode and the work piece in the presence of a dielectric fluid [3]. Wire Electrical discharge machining (WEDM) uses the same fundamental principles of material removal as EDM, but uses a traveling, small-diameter wire as the electrode. The wire travels from a supply spool, through the workpiece, and on to a take-up spool.

Hasçalýk et al. [4] presented an experimental investigation of the machining characteristics of AISI
D5 tool steel in the wire electrical discharge machining process. During their experiments, parameters such as open circuit voltage, pulse duration, wire speed and dielectric fluid pressure were changed to explore their effect on the surface roughness and metallurgical structure. They used optical and scanning electron microscopy, surface roughness and microhardness tests to study the characteristics of the machined specimens. They found that the intensity of the process energy does affect the amount of recast and surface roughness as well as microcracking, the wire speed and dielectric fluid pressure not seeming to have much of an influence.

Wire electric discharge machining induced a new phase in $\mathrm{Ti}-46 \mathrm{Al}-2 \mathrm{Cr}$ (in at.\%) intermetallic alloy has been identified using X-ray diffraction technique by Qin et al, [5]. They observed that a new phase was found to be neither $\mathrm{TiO}_{2}$ nor $\mathrm{Al}_{2} \mathrm{O}_{3}$, but well 
consistent with FCC structure titanium hydride with the lattice parameter of $4.49-4.50 \mathrm{~A}^{\circ}$. Further, the new phase exists in the wire-EDM cut alloy surface layer limiting to about $70 \mathrm{~mm}$ thick, much deeper than the wire-EDM induced recast layer thickness of 2-3 $\mathrm{mm}$. On processing, vacuum annealing at $400-$ $600{ }^{\circ} \mathrm{C}$, has been proposed to remove this hydride induced by wire-EDM. In addition, they showed that the wire-EDM induced microcracks extensively happened on the EDM-cut surface and penetrated into matrix up to $10-30 \mathrm{~mm}$.

Modeling in WEDM helps to get a better understanding of the complex process [6-8]. The modeling was first introduced by Jeswani using dimensional analysis to predict the tool wear. After that, various methods were introduced to predict the output of EDM process [9]. In addition, the modeling of the WEDM process by means of mathematical techniques has also been applied to effectively relate the large number of process variables to the different performance of the process.

A semi empirical model of surface finish [10], MRR and tool wear [11] for various materials have been established by employing dimensional analysis. Using the design of experiment method, the process parameter viz. peak current, pulse duration, electric polarity and material properties are identified. The final results show that the average error between the experiment and prediction was less than $10 \%$ for surface finish model and less than $20 \%$ for MRR. However, the relations between tool wear and discharge time under different electric polarity are seen to have inverse effect.

Chiang et al. [12] presented an approach for optimization of the WEDM process of $\mathrm{Al} 2 \mathrm{O} 3$ particle reinforced material (6061 alloy) with multiple performance characteristics based on the grey relational analysis and Taguchi technique. The response table and response graph for each level of the machining parameters are obtained from the grey relational grade, and the optimal levels of machining parameters. In their study, the machining parameters, namely the cutting radius of working piece, the ontime of discharging, the off-time of discharging, the arc on-time of discharging, the arc off-time of discharging, the servo voltage, the wire feed and water flow are optimized with considerations of multiple performance, such as the removal rate and surface roughness.

El-Taweel [13] studied the effect and optimization of machining parameters on the material removal rate (MRR) and surface roughness (SR) in the WEDM process of some Al-Cu-TiC-Si P/M composite. The settings of machining parameters were determined by using Taguchi experimental design method. The variation of MRR and surface roughness with machining parameters was mathematically modeled by using the nonlinear regression analysis method. The optimal search for machining parameters for the objective of maximum MRR and minimum SR was performed. Based on the experimental confirmation it was observed that the material removal rate increased by 1.58 times and surface roughness was decreased by 1.11 times.

Sharif and Noordin [14] established empirical relation of machining responses using the response surface methodology technique while machining Ti6246 workpiece by adding $\mathrm{SiC}$ powder in the dielectric. The results show that MRR, tool wear, and surface quality are greatly influenced by the current, voltage, and pulse on-time, and the surface roughness is highly influenced by the presence of SiC additives.

RSM technique has also been applied to optimize the input of WEDM parameters of Inconel 601 by Hewidy el al. [15]. They reported that the analysis of the response parameters using RSM technique had the advantage of explaining the effect of each working parameter on the value of the resultant response parameter.

The published literature indicates that little studies have been reported for the optimization of process parameters in WEDM for CK45 steel. ElTaweel [16] investigated the correlation of process parameters in die sinking EDM of CK45 steel with $\mathrm{Al}-\mathrm{Cu}-\mathrm{Si}-\mathrm{TiC}$ composite electrode produced using powder metallurgy technique and evaluated MRR and TWR. It has been found that such electrodes are more sensitive to peak current and on-time than conventional electrodes. To achieve maximum MRR and minimum TWR, the process parameters are optimized, and experimental verification were found to be in good agreement. However, it has not been found that there is no available result of the WEDM process of this material. Therefore, it is imperative to develop a suitable technology guideline for optimum WEDM of CK45 steel. So the aim of the present investigation is to develop models for correlating the inter-relationships of various wire electrical discharge machining (WEDM) parameters of CK45 steel such as feeding speed (Fs), duty factor (D), wire tension $(\mathrm{T})$, wire speed (Ws) and water pressure $(\mathrm{P})$ on the metal removal rate (MRR), tool wear rate (TWR) and surface roughness (SR).

\section{EXPERIMENTAL DETAILS}

\subsection{Experimental Procedure and Measurements}

In the present study, MRR, TWR and SR have been considered for evaluating the machining performance. MRR, TWR and SR are correlated with input machining parameters such Feeding Speed (Fs), Duty Factor (D), Wire Tension (T), Wire Speed (Ws) and Water Pressure $(\mathrm{P})$. There has been a rapid growth in the development of harder and more difficult to machine metals and alloys during the last 
five decades [1]. The experiments were conducted on a W-B30J.S C.N.C wire electrical discharge machine (Taiwan). Figure 1 shows the used experimental set up.

The wire electrode material used in the WEDM process was made from Brass-CuZn37 with diameter $0.25 \mathrm{~mm}$.

The workpiewce material used in these experiments was CK45 steel with dimensions $8 \times 8 \times 8$ $\mathrm{mm}^{3}$. Table 1 shows the chemical composition of CK45 steel. The selection of this material was made, taking into account its wide range of applications in military and automotive industries [17]. It can be classified as a difficult-to-cut material, not suitable for traditional machining. During machining, commercial de-ionized water was circulated as the dielectric fluid with side flushing technique. The machining time for each experiment was variable and related to the machining conditions and fixed parameters which are listed in Table 2. These were chosen through reviews of experience, literature surveys [8-14], and some preliminary investigations.

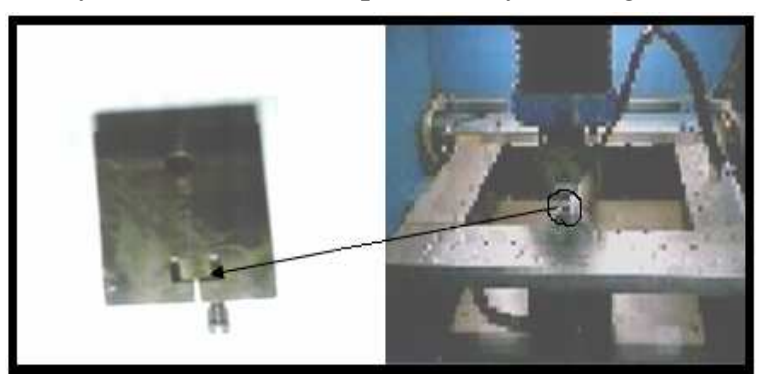

Fig. 1 The used experimental set up

The specimen and wire were weighted before and after machining using a digital balance (Sartorius, type $1712,0.0001 \mathrm{~g})$.

The metal removal rate was specified using the following equation:

$$
\operatorname{MRR}=\frac{w_{b}-w_{m}}{t}
$$

Where,

$$
\begin{aligned}
& W_{b} \text { : specimen weight before machining }(\mathrm{g}) \text {. } \\
& W_{a} \text { : specimen weight after machining }(\mathrm{g}) \text {. } \\
& \mathrm{t} \text { : machining time }(\mathrm{min}) \text {. }
\end{aligned}
$$

The tool wear rate was specified using following equation:

$$
T W R=\frac{T_{\mathrm{b}}-T_{\mathrm{n}}}{t}
$$

Where,

$\mathrm{T}_{\mathrm{b}}$ : wire weight before machining $(\mathrm{g})$.

$\mathrm{T}_{\mathrm{a}}$ : wire weight before machining $(\mathrm{g})$. $\mathrm{t}$ : machining time $(\mathrm{min})$.

The roughness average $\left(R_{a}\right)$ for each specimen was measured by surface roughness tester (Mitutoye, Japan, Surftest-402). Each surface roughness value was obtained by averaging four measurements. The instrument is adjusted to the following conditions during measurement; measuring length $(50 \mathrm{~mm})$, measuring speed $(0.5 \mathrm{~mm} / \mathrm{s})$ and sampling length $(0.8 \mathrm{~mm})$.

\subsection{Experimental Design}

Response surface methodology (RSM) is an interaction of mathematical and statistical techniques for modelling and optimizing the response variable models involving quantitative independent variables [15-19]. In the present work, the range of the feeding speed (Fs), duty factor (D), wire tension (T), wire speed (Ws) and water pressure (P) settings have been selected after performing some pilot experiments. Actual and coded values of the input process parameters have been listed in Table 3. Experiments have been carried out according to the experimental plan based on central composite rotatable second order design (CCD) [17-19]. The Design of experiment matrix showing actual values of the input process parameters is shown in Table 4.

\section{MATHEMATICAL MODELLING}

Through the use of the design of experiments and applying regression analysis, the modelling of the desired response to several independent variables can be gained [17]. If all variables are assumed to be measurable, the quadratic response surface model of $Y_{u}$ can be written as follows:

$$
Y_{u}=b_{o}+\sum_{i=1}^{k} b_{i} X_{i}+\sum_{j>i}^{k} b_{i j} X_{i} X_{j}+\sum_{i=1}^{k} b_{i i} X_{i}^{2} \pm \varepsilon
$$

where $Y_{u}$ is the corresponding response function (or response surface), $X_{1}, X_{2}, X_{3} \ldots . . X_{\mathrm{k}}$ are coded values of the machining process parameters and $\varepsilon$ is the fitting error of the $u_{t h}$ observations. In this study, for four variables under consideration (Fs, D, T, Ws and $\mathrm{P}$ ), a second order polynomial regression model, called quadratic model, is proposed.

The coefficient $b_{\mathrm{o}}$ is the free term, the coefficients $b_{\mathrm{i}}$ are the linear terms, the coefficients $b i j$ are the interaction terms and the coefficients $b_{\mathrm{ii}}$ are the quadratic terms. Using the results presented in Tables 3 and 4 , the full form of the derived models can be presented.

Based on Eq. (3), the effect of input parameters (Table 4) on values of metal removal rate, tool wear rate and surface roughness has been evaluated by computing the values of various constants using Table 4. The mathematical models of metal removal rate (MRR), tool wear rate (TWR), and surface roughness (SR), can be expressed as fallows: 
$\mathrm{MRR}=0.1223-0.011118 \mathrm{X}_{1}+0.19026 \mathrm{X}_{2}-4.28903 \mathrm{E}-$ $3 \mathrm{X}_{3}-0.036323 \mathrm{X}_{5}+7.14864 \mathrm{E}-3 \mathrm{X}_{1} \mathrm{X}_{2}+5.68595 \mathrm{E}-$ $4 \mathrm{X}_{1} \mathrm{X}_{3}+3.01735 \mathrm{E}-3 \mathrm{X}_{1} \mathrm{X}_{5}+8.05 \mathrm{E}-$

$3 \mathrm{X}_{2} \mathrm{X}_{3}+0.026750 \mathrm{X}_{2} \mathrm{X}_{5}+7.1 \mathrm{E}-4 \mathrm{X}_{3} \mathrm{X}_{5^{-}}$ $3.15866 \mathrm{E}-3 \mathrm{X}^{2}{ }_{1}-\mathrm{X}^{2}{ }^{-1}-10665 \mathrm{E}-3 \mathrm{X}^{2}{ }_{5}$

$\mathrm{TWR}=0.18-0.011195 \times 1+0.017165 \times 2-7.5164 \mathrm{E}-$ 3X3-0.087888X5-0.021776X1X2-3.78253E$4 \mathrm{X} 1 \mathrm{X} 3+1.5486 \mathrm{E}-3 \mathrm{X} 1 \mathrm{X} 5-3.5 \mathrm{E}-3 \mathrm{X} 2 \mathrm{X} 3+5 \mathrm{E}-$ $33 \mathrm{X} 2 \mathrm{X} 4-2 \mathrm{E}-4 \mathrm{X} 3 \mathrm{X} 5+4.2713$ $\mathrm{E}-3 \mathrm{X} 21+0.26101 \mathrm{X} 22+5.37609 \mathrm{E}-$ $4 \mathrm{X} 23+0.01744 \mathrm{X} 25$

$\mathrm{SR}=9.99333+1.7298 \times 1-10.9628 \times 2-0.23586 \times 3-$ 3.359E-3X4-4.07745X5-1.76764X1X2$0.04526 \mathrm{X} 1 \mathrm{X} 3-0.2548 \mathrm{X} 1 \mathrm{X} 5$ $+0.41 \mathrm{X} 2 \mathrm{X} 3+2.15625 \mathrm{E}-3 \mathrm{X} 2 \mathrm{X} 4+5.275 \mathrm{X} 2 \mathrm{X} 5-$ $0.03 \times 3 \times 5+0.04786 \times 21-3.1961 \times 22$ $+8.88623 \mathrm{E}-3 \mathrm{X} 23+0.47216 \mathrm{X} 25$

(6)
The adequacy of the provided models is checked by analysis of variance (ANOVA). It can be noted that there are some terms omitted from the equations. These terms are non-significant terms according to the ANOVA of the models.

\section{RESULTS AND DISCUSSION}

\subsection{Effect of Machining Parameters on MRR}

Metal removal rate in the WEDM process is a vital and significant factor due to its effect on the industrial economy. Based on the RSM model, Fig 2 shows the effect of feeding speed on MRR at various duty factors, while keeping the other parameters at centre level. Figure 2 reflects that MRR increases as the feeding speed of the wire increases. This result has been attributed to the increase of the consumed applied current which leads to the increases in the rate of the heat energy and hence in the rate of melting and evaporation [15].

Table 1, Chemical composition for CK45 steel (wt\%)

\begin{tabular}{|c|c|c|c|c|c|c|c|}
\hline $\mathrm{C}$ & $\mathrm{Si}$ & $\mathrm{Mn}$ & $\mathrm{P}$ & $\mathrm{S}$ & $\mathrm{Cr}$ & $\mathrm{Mo}$ & $\mathrm{Ni}$ \\
\hline 0.4771 & 0.2105 & 0.628 & 0.0109 & 0.0111 & 0.1079 & 0.0236 & 0.0788 \\
\hline \hline $\mathrm{Al}$ & $\mathrm{Co}$ & $\mathrm{Cu}$ & $\mathrm{V}$ & $\mathrm{W}$ & $\mathrm{Sn}$ & $\mathrm{Fe}$ & \\
\hline 0.0073 & 0.0073 & 0.1896 & 0.0035 & $<0.0050$ & 0.0103 & 98.23 & \\
\hline
\end{tabular}

Table 2, EDM machining conditions

\begin{tabular}{|l|l|}
\hline Working condition & Value \\
\hline Workpiece material & CK45 steel \\
\hline Tool & $(+)$ Polarity \\
\hline Wire material & Brass CuZn37 \\
\hline Feeding speed $(\mathrm{mm} / \mathrm{min})$ & $1.7-4.9$ \\
\hline Pulse-on time $(\mu \mathrm{s})$ & $1-9$ \\
\hline Pulse-off time $(\mu \mathrm{s})$ & 9 \\
\hline Wire tension $\left(\mathrm{g}_{\mathrm{f}}\right)$ & $800-2400$ \\
\hline Wire speed $(\mathrm{m} / \mathrm{s})$ & $5-15$ \\
\hline Water pressure $(\mathrm{MPa})$ & $1-3$ \\
\hline Wire diameter $(\mathrm{mm})$ & 0.25 \\
\hline Peak current & Automatically selected \\
\hline Dielectric fluid & De-ionized water \\
\hline
\end{tabular}

Table 3, Coded and actual values of the input parameters

\begin{tabular}{|l|c|c|c|c|c|c|}
\hline \multicolumn{1}{|c|}{ Input parameters } & \multirow{2}{*}{ Symbol } & \multicolumn{7}{c|}{ Levels } \\
\cline { 3 - 7 } & & -1 & -1 & 0 & +1 & +2 \\
\hline Feeding speed (Fs), mm/min & $\mathrm{X}_{1}$ & 1.7 & 2.5 & 3.3 & 4.1 & 4.9 \\
\hline Duty factor (D) & $\mathrm{X}_{2}$ & 0.1 & 0.2 & 0.3 & 0.4 & 0.5 \\
\hline Wire tension (T), gf & $\mathrm{X}_{3}$ & 800 & 1200 & 1600 & 2000 & 2400 \\
\hline Wire speed (Ws), m/s & $\mathrm{X}_{4}$ & 5 & 7.5 & 10 & 12.5 & 15 \\
\hline Water pressure (P), MPa & $\mathrm{X}_{5}$ & 1 & 1.5 & 2 & 2.5 & 3 \\
\hline
\end{tabular}


Table 4, Experimental design matrix and experimental results

\begin{tabular}{|c|c|c|c|c|c|c|c|c|}
\hline \multirow{3}{*}{$\begin{array}{l}\text { Exp. } \\
\text { No. }\end{array}$} & \multicolumn{5}{|c|}{ Input process parameters } & \multirow{2}{*}{\multicolumn{3}{|c|}{ Experimental results }} \\
\hline & \multirow{2}{*}{$\begin{array}{l}\text { Feeding } \\
\text { speed, } \\
\mathrm{mm} / \mathrm{min}\end{array}$} & \multirow{2}{*}{ Duty factor } & \multirow{2}{*}{$\begin{array}{c}\text { Wire } \\
\text { tension, } \\
\mathrm{g}_{\mathrm{f}}\end{array}$} & \multirow{2}{*}{$\begin{array}{c}\text { Wire speed, } \\
\mathrm{m} / \mathrm{s}\end{array}$} & \multirow{2}{*}{$\begin{array}{c}\text { Water } \\
\text { pressure, } \\
\text { MPa }\end{array}$} & & & \\
\hline & & & & & & MRR, g/min & $\begin{array}{l}\text { TWR, } \\
\text { g/min }\end{array}$ & $\begin{array}{l}\mathrm{Ra}, \\
\mu \mathrm{m}\end{array}$ \\
\hline 1 & 2.5 & 0.2 & 7.5 & 1200 & 2.5 & 0.0391 & 0.0260 & 2.3 \\
\hline 2 & 4.1 & 0.2 & 7.5 & 1200 & 1.5 & 0.0453 & 0.0440 & 2.4 \\
\hline 3 & 2.5 & 0.4 & 7.5 & 1200 & .1 .5 & 0.0685 & 0.0470 & 2.5 \\
\hline 4 & 4.1 & 0.4 & 7.5 & 1200 & 2.5 & 0.0735 & 0.0510 & 2.7 \\
\hline 5 & 2.5 & 0.2 & 12.5 & 1200 & 1.5 & 0.0371 & 0.0360 & 2.8 \\
\hline 6 & 4.1 & 0.2 & 12.5 & 1200 & 2.5 & 0.0426 & 0.0450 & 2 \\
\hline 7 & 2.5 & 0.4 & 12.5 & 1200 & 2.5 & 0.0698 & 0.0480 & 2.5 \\
\hline 8 & 4.1 & 0.4 & 12.5 & 1200 & 1.5 & 0.0739 & 0.0510 & 2.6 \\
\hline 9 & 2.5 & 0.2 & 7.5 & 2000 & 1.5 & 0.0347 & 0.0340 & 2.7 \\
\hline 10 & 4.1 & 0.2 & 7.5 & 2000 & 2.5 & 0.0650 & 0.0460 & 2.8 \\
\hline 11 & 2.5 & 0.4 & 7.5 & 2000 & 2.5 & 0.0601 & 0.0490 & 3.3 \\
\hline 12 & 4.1 & 0.4 & 7.5 & 2000 & 1.5 & 0.0755 & 0.0520 & 2.5 \\
\hline 13 & 2.5 & 0.2 & 12.5 & 2000 & 2.5 & 0.0374 & 0.0410 & 2.7 \\
\hline 14 & 4.1 & 0.2 & 12.5 & 2000 & 1.5 & 0.0569 & 0.0430 & 2.8 \\
\hline 15 & 2.5 & 0.4 & 12.5 & 2000 & 1.5 & 0.0474 & 0.0470 & 2.6 \\
\hline 16 & 4.1 & 0.4 & 12.5 & 2000 & 2.5 & 0.0943 & 0.0490 & 2.5 \\
\hline 17 & 1.7 & 0.3 & 10 & 1600 & 2 & 0.0423 & 0.0270 & 1.9 \\
\hline 18 & 4.9 & 0.3 & 10 & 1600 & 2 & 0.0743 & 0.0460 & 4.9 \\
\hline 19 & 3.3 & 0.1 & 10 & 1600 & 2 & 0.0284 & 0.0240 & 2.5 \\
\hline 20 & 3.3 & 0.5 & 10 & 1600 & 2 & 0.0943 & 0.0480 & 2.2 \\
\hline 21 & 3.3 & 0.3 & 5 & 1600 & 2 & 0.0619 & 0.0410 & 3.2 \\
\hline 22 & 3.3 & 0.3 & 15 & 1600 & 2 & 0.0701 & 0.0280 & 2.2 \\
\hline 23 & 3.3 & 0.3 & 10 & 800 & 2 & 0.0609 & 0.0310 & 3.5 \\
\hline 24 & 3.3 & 0.3 & 10 & 2400 & 2 & 0.0758 & 0.0380 & 2.1 \\
\hline 25 & 3.3 & 0.3 & 10 & 1600 & 1 & 0.0615 & 0.0460 & 3.4 \\
\hline 26 & 3.3 & 0.3 & 10 & 1600 & 3 & 0.0705 & 0.0250 & 2.5 \\
\hline 27 & 3.3 & 0.3 & 10 & 1600 & 2 & 0.0659 & 0.0270 & 2.4 \\
\hline 28 & 3.3 & 0.3 & 10 & 1600 & 2 & 0.0653 & 0.0280 & 2.4 \\
\hline 29 & 3.3 & 0.3 & 10 & 1600 & 2 & 0.0655 & 0.0270 & 2.5 \\
\hline 30 & 3.3 & 0.3 & 10 & 1600 & 2 & 0.0639 & 0.0270 & 2.4 \\
\hline 31 & 3.3 & 0.3 & 10 & 1600 & 2 & 0.0645 & 0.0290 & 2.4 \\
\hline 32 & 3.3 & 0.3 & 10 & 1600 & 2 & 0.0652 & 0.0270 & 2.5 \\
\hline
\end{tabular}

Furthermore, Fig. 2 shows that MRR also increases with the increase of the duty factor. This trend is due to the fact that the increase of the duty factor means the application of the same heating temperature for a long time [20]. In addition to that, Fig. 2 shows that the effect of the duty factor is more pronounced than the feeding speed. This phenomenon reflects that the increase in peak current, as a function to the increase of the feeding speed, leads to arcing which relatively limits the discharge number and machining efficiency.

Figure 3 shows the effect of feeding speed on MRR at various wire speed, it is reflected that wire speed generally has almost no effect on the MRR. However, if the wire speed is reduced to a certain limit $(5 \mathrm{~m} / \mathrm{s})$, the cutting process becomes nonuniform and the wire electrode breaks down several times because of the increase of the number of discharge per unit length of wire. This result has also been reported by Kinoshita [21] who deduced that the wire winding speed had almost no effect on the increase of the feeding rate. 
T. A. El-Taweel, A. H. Youssef, A. M. Hewidy, "Optimum Selection of WEDM Conditions for CK45 Steel"

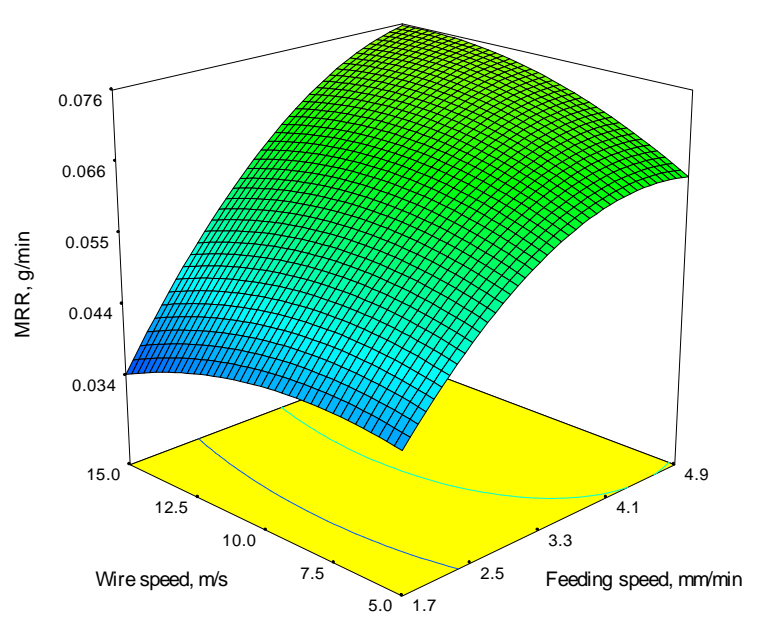

Fig. 2 Effect of feeding speed on MRR at various duty factor $(\mathrm{T}=1600 \mathrm{gf}, \mathrm{Ws}=10 \mathrm{~m} / \mathrm{s}, \mathrm{P}=2 \mathrm{MPa})$

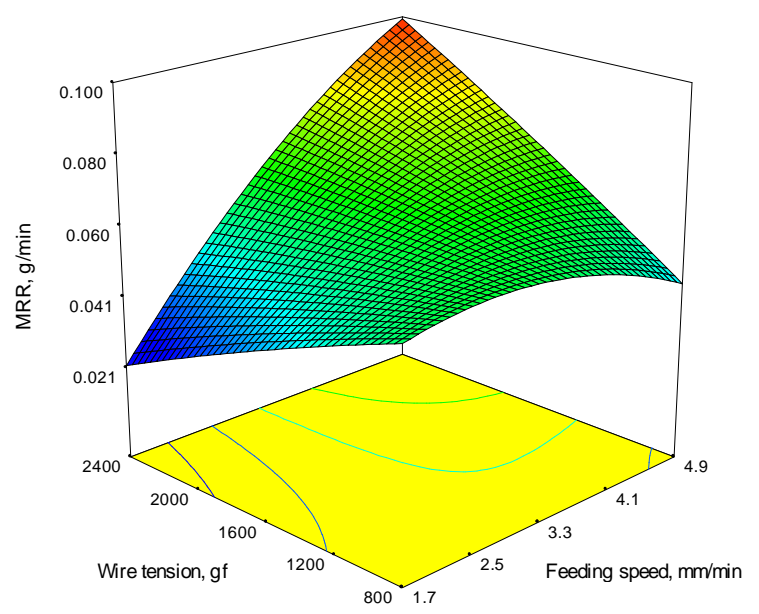

Fig. 3 Effect of feeding speed on MRR at various wire speed $(\mathrm{D}=0.3, \mathrm{~T}=1600 \mathrm{gf}, \mathrm{P}=2 \mathrm{MPa})$

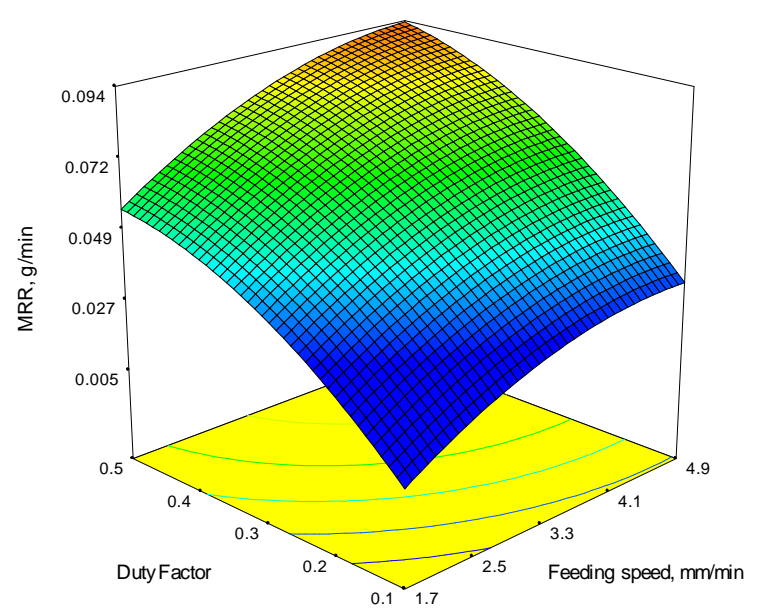

Fig. 4 Effect of feeding speed on MRR at various wire tension $(\mathrm{D}=0.3, \mathrm{Ws}=10 \mathrm{~m} / \mathrm{s}, \mathrm{P}=2 \mathrm{MPa})$

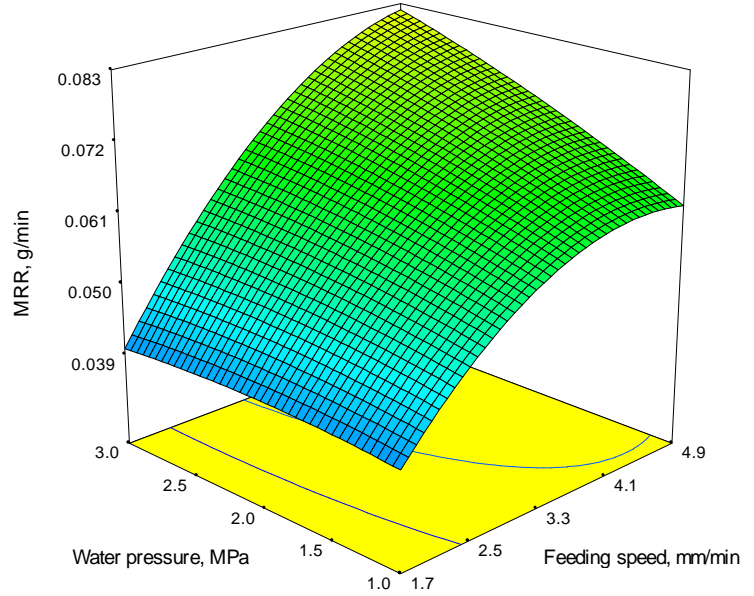

Fig. 5 Effect of feeding speed on MRR at various water pressure $(D=0.3, \mathrm{Ws}=10 \mathrm{~m} / \mathrm{s}, \mathrm{T}=1600 \mathrm{gf})$

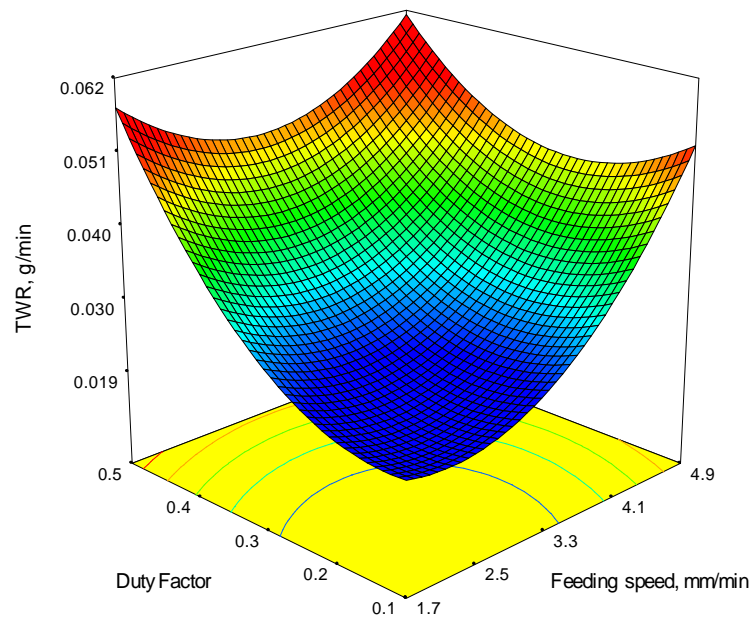

Fig. 6 Effect of feeding speed on TWR at various duty factor $(\mathrm{T}=1600 \mathrm{gf}, \mathrm{Ws}=10 \mathrm{~m} / \mathrm{s}, \mathrm{P}=2 \mathrm{MPa})$

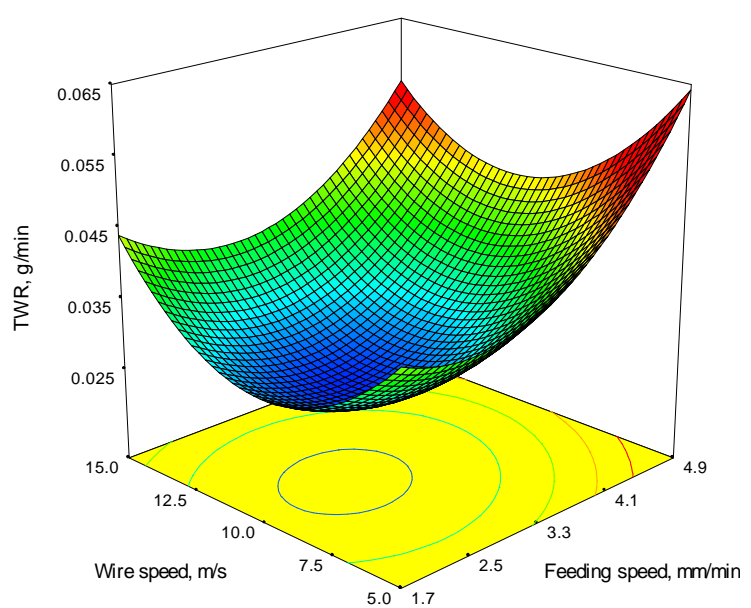

Fig. 7 Effect of feeding speed on TWR at various wire speed $\left(\mathrm{T}=1600 \mathrm{~g}_{\mathrm{f}}, \mathrm{D}=0.3, \mathrm{P}=2 \mathrm{MPa}\right)$ 


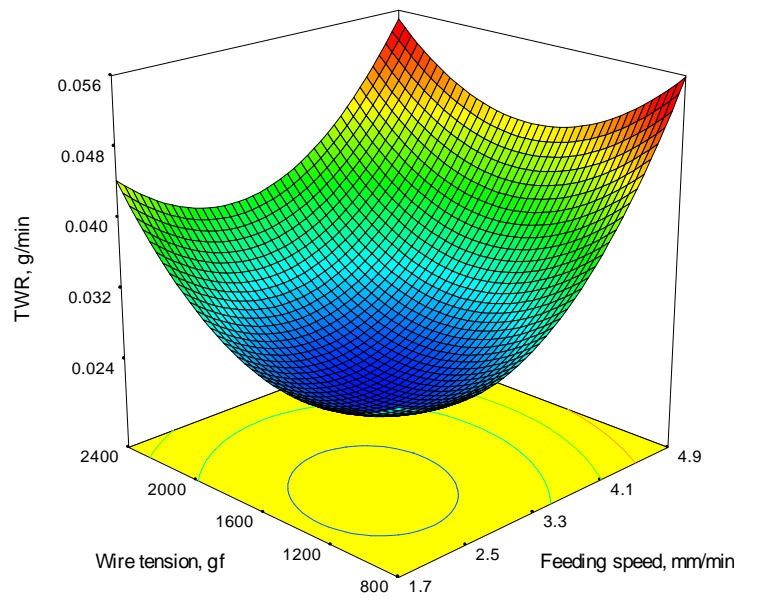

Fig. 8 Effect of feeding speed on TWR at various wire tension $\left(\mathrm{D}=0.3, \mathrm{~T}=1600 \mathrm{~g}_{\mathrm{f}}, \mathrm{Ws}=10 \mathrm{~m} / \mathrm{s}\right.$,

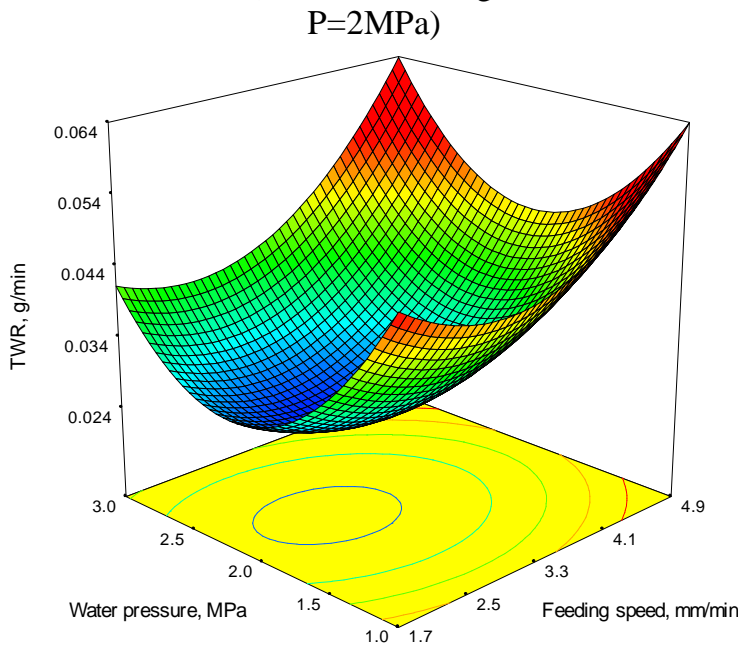

Fig. 9 Effect of feeding speed on TWR at various water pressure $\left(D=0.3, T=1600 g_{f}, W s=10 \mathrm{~m} / \mathrm{s}\right.$, $\mathrm{Ws}=10 \mathrm{~m} / \mathrm{s}$ )

Figure 9 shows that the min. TWR has been achieved at wire tension equals $1600 \mathrm{~g}_{\mathrm{f}}$, wire speed equals $12.5 \mathrm{~m} / \mathrm{s}$ and at water pressure equals 2.5 MPa.

In Figs. (7-9), it has also been observed that the increase of wire speed, wire tension and water pressure leads to the reduction of the TWR. This result is due the improvement of the flushing conditions and the stability of the process. After wire speed exceeded $10 \mathrm{~m} / \mathrm{s}$, wire tension exceeded 2000 $\mathrm{g}_{\mathrm{f}}$ and water pressure exceeded $2.5 \mathrm{MPa}$, it has been noticed that TWR starts to increase, which consequently, implies the presence of arcing. Obviously, these conditions may lead to vigorous sparking on the wire surface and the propagation of wear at the wire surface. It has also been sion and spark pressure are the two major causes of wire rupture [23].

\subsection{Effect of Machining Parameters on SR}

Surface finish produced on machined surface plays an important role in production. It becomes more desirable so as to produce a better surface when hardened materials are machined, requiring no subsequent polishing. Surface finish is also important in case of tools and dies for molding as well as drawing operations. Surface roughness and dimensional accuracy of a spark eroded work material depend on pulse energy, water pressure, wire tension and wire speed. Furthermore, it could be extended to include wire polarity, wire material, work piece material and work piece thickness [24].

Figures (10-12) show the relationship between duty factor and both wire speed and wire tension. The lowest value (LB) of surface roughness has been achieved at low duty factor, lowest on-time, lowest pulse energy, and the higher values of wire tension and wire speed. The value of surface roughness ( $\mathrm{Ra})$ has reached $1.45 \mu \mathrm{m}$. It should be noted that wire vibration usually becomes more serious as wire tension decreases. This result infers that a fine surface can be achieved by using stable and large wire tension and higher wire speed values. This trend confides with the same trend which has been obtained by Liao et al. [25].

Figure 10 shows that the best parametric combination to get the optimum surface roughness (less than $2 \mu \mathrm{m}$ ) has been achieved at low duty factor and low feeding speed. It should be noted that the reduction of on time decreases the spark energy. It is spark energy that controls the depth of the discharge pits, which directly relates to the surface finish . However, the off-time is the pause between discharge that allows the debris to solidify and be flushed away by the dielectric prior to the next discharge. So, it has been avoided to increase off-time that can dramatically increase the cutting speed, by allowing more productive discharges per unit of time. Furthermore, reducing off-time, can overload the wire, causing wire breaks and instability of the cut by not allowing enough time to evacuate the debris before the next discharge $[4,26]$.

Figure 13 anticipated that the optimum relationship between water pressure and feeding speed has been got at water pressure equals $2 \mathrm{MPa}$ and feeding speed about $2.5 \mathrm{~mm} / \mathrm{min}$ (low pulse energy and moderate water pressure). This phenomenon reflects the stability of the WEDM action at these conditions. The results obtained in the present work about surface roughness values are similar, or less, than that reported by Gokler and Ozanogu [27] about 1040 steel material when machined by WEDM. 


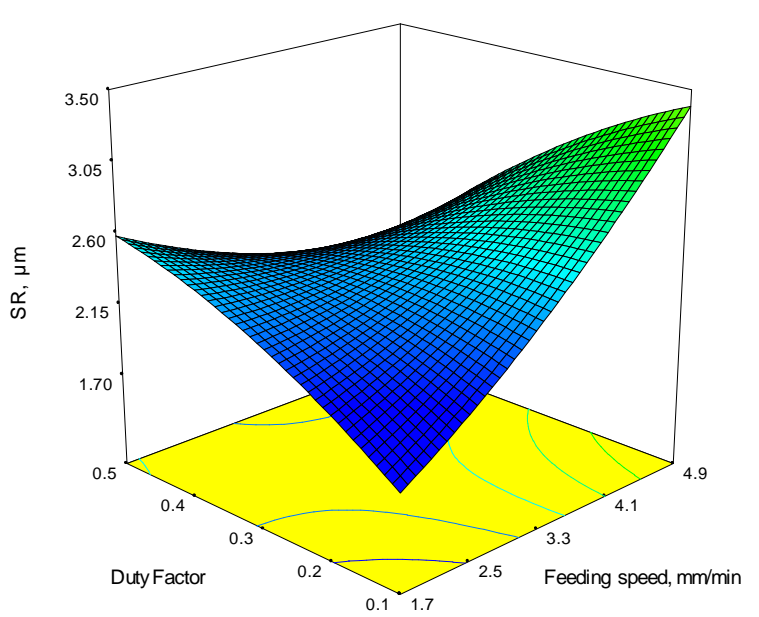

Fig. 10 Effect of feeding speed on $S R$ at a various duty factor $(\mathrm{T}=1600 \mathrm{gf}, \mathrm{Ws}=10 \mathrm{~m} / \mathrm{s}, \mathrm{P}=2 \mathrm{MPa})$

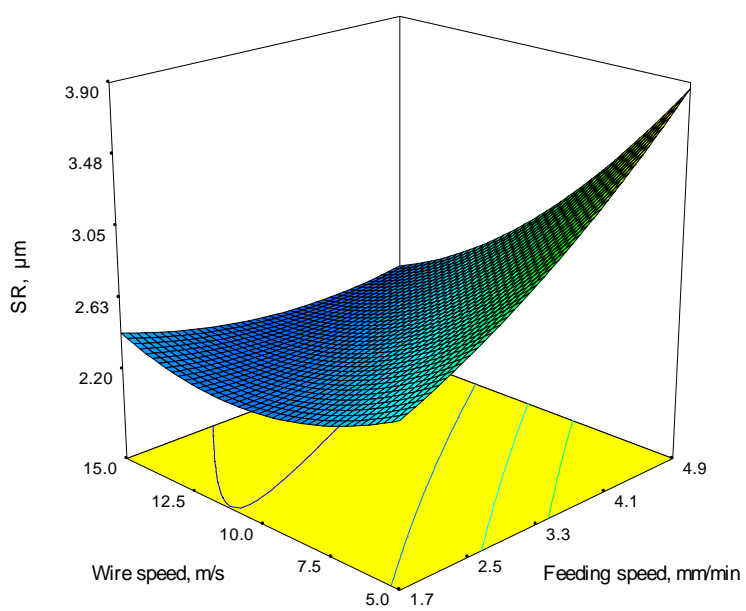

Fig. 11 Effect of feeding speed on SR at various wire speed $\left(\mathrm{T}=1600 \mathrm{~g}_{\mathrm{f}}, \mathrm{D}=0.3, \mathrm{P}=2 \mathrm{MPa}\right)$

\section{OPTIMIZATION OF THE PROCESS}

The objective of using RSM is not only to investigate the response over the entire factor space, but also to locate the region of interest where the response reaches its optimum or near optimal value. Derringer and Suich [28] describe a multiple response method called desirability. It is an attractive method to industry for optimization of multiple quality characteristic problems. The method makes use of an objective function, D (X), called the desirability function (utility transfer function) and transforms an estimated response into a scale free value (di) called desirability. The desirable ranges are from zero to one (least to most desirable respectively). One represents the ideal case; zero indicates that one or more responses are outside their acceptable limits. Composite desirability is the weighted geometric mean of the individual desirabilities for the responses. The factor settings with maximum total desirability are considered to be the optimal parameter conditions. The simultaneous objective function is a geometric mean of all

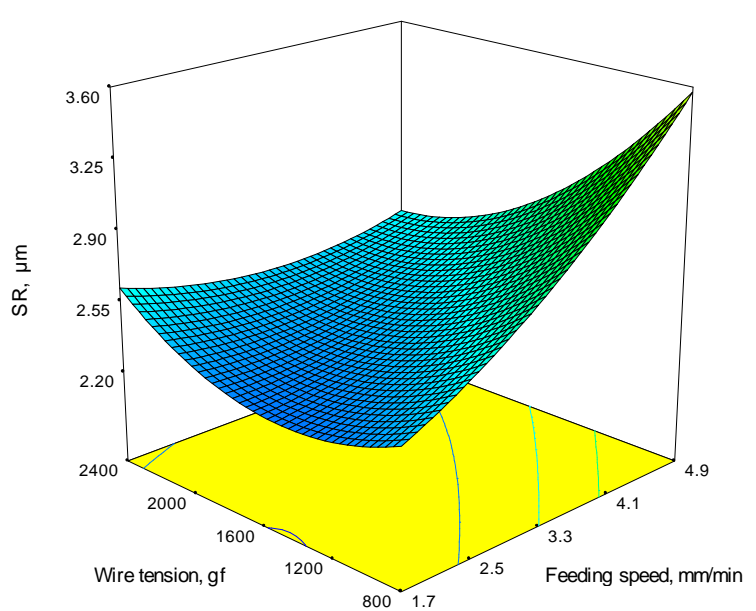

Fig. 12 Effect of duty factor on $S R$ at various wire tension $(\mathrm{Fs}=3.3 \mathrm{~mm} / \mathrm{min}, \mathrm{T}=1600 \mathrm{gf}, \mathrm{P}=2 \mathrm{MPa})$

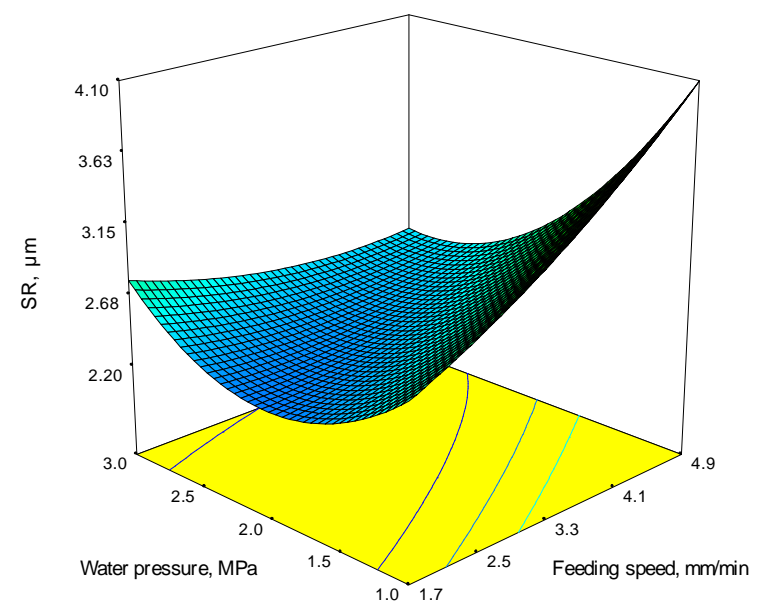

Fig.13 Effect of duty factor on SR at various water pressure $(\mathrm{Fs}=3.3 \mathrm{~mm} / \mathrm{min}, \mathrm{T}=1600 \mathrm{gf}, \mathrm{P}=2 \mathrm{MPa})$

transformed responses [28, 29]. Three responses i.e. MRR, TWR and SR have been optimized simultaneously using developed models, i.e Eqs. (46) based on composite desirability optimization technique. In response to optimization, a measure of how the solution has satisfied the combined goals for all responses must be assured. The optimality solution is to evaluate the input parameters in experiment range for maximizing MRR, minimizing TWR and SR. The numeric values of optimum conditions and the predicted optimum values of responses under these conditions are presented in Tables 5 and 6.

Table 5, Constraints of parameters and optimum values

\begin{tabular}{|r|c|c|}
\hline \multicolumn{1}{|c|}{ Parameter } & Constrains & Optimum value \\
\hline Feeding speed (Fs), & $1.7-4.9$ & 13.43 \\
\hline Duty factor (D) & $0.1-0.5$ & 0.33 \\
\hline Wire tension (T), g & $5-15$ & 11.28 \\
\hline Wire speed (Ws), m/s & $800-2400$ & 1646.39 \\
\hline Water pressure (P), MPa & $1-3$ & 2.19 \\
\hline
\end{tabular}


Table 6, Predicted optimum values of responses

\begin{tabular}{|r|c|c|}
\hline Response & Goal & Predicted \\
\hline MRR, g/min & Maximize & 0.072 \\
\hline TWR, g/min & Minimize & 0.03 \\
\hline $\mathrm{SR}, \mu \mathrm{m}$ & Minimize & 2.30 \\
\hline
\end{tabular}

Figure 14 represents the optimized graphs of the three responses (MRR, TWR and SR) and also the optimization results. The vertical lines inside the cells represent current optimal parametric settings, and the horizontal dotted lines represent the current response values. The value of composite desirability (D) was taken as 0.6911.

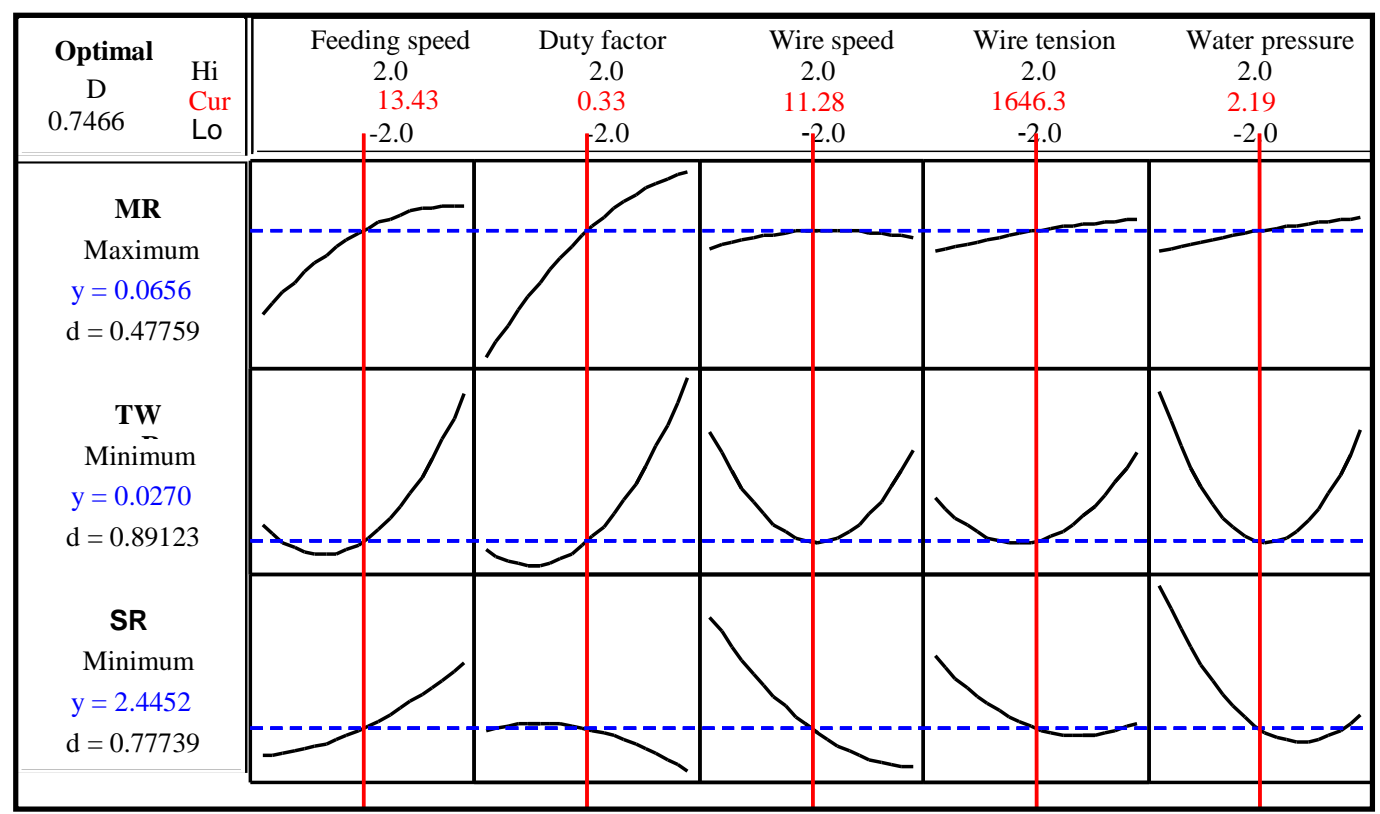

Fig. 14 Multi-response optimization results for maximum MRR, and minimum TWR and

\section{CONCLUSIONS}

The results concluded from the present work can be summarized as follows:

1. The WEDM process has proved its adequacy to machine CK45 steel material under acceptable metal removal rate and fine surface finish $\left(R_{a}\right)$ less than $1.5 \mu \mathrm{m}$.

2. The metal removal rate generally increases with the increase of feeding speed value, duty factor and water pressure. The effect of wire tension and wire speed was limited.

3. Lower tool wear rate has been obtained at the parametric combination of lower feeding speed and lower duty factor. It has also been found that the increase of water pressure, wire tension and wire speed decreases tool wear. This trend was valid up to the generation of arcing.

4. Fine surface quality (SR) has been obtained at lower feeding speed, lower duty factor and higher water pressure. The effect of wire tension and wire speed was relatively positive and insignificant.

5. An optimization study has also been submitted to get maximum MRR or minimum TWR or minimum SR under the different working conditions.
Finally, the present work facilitates a guideline for optimum selection of the machining parameters to the product designer in WEDM process of CK454 steel.

\section{REFERENCES}

[1] R. Snoeys, F. Staelens, W., Dekeyser. "Current trends in non-conventional material removal processes: Annals of CIRP, Vol. 35/2 (1986), pp 467-480.

[2] K. H. Ho, S. T. Newman, "State of the art electrical discharge machining (EDM)", Int. J. Machine Tools Manufac, 43 (2003), pp 12871300 .

[3] B. Bojorquez, R.T. Marloth, O.S. Es-Said, "Formation of a crater in the workpiece on an electrical discharge machine", Engineering Failure Analysis, 9 (2002), pp 93-97.

[4] A. Hasçalýk, V. Caydas. "Experimental study of wire electrical discharge machining of AISI D5 tool steel." J. Mater. Processing Technol, 148 (2004), pp 362-367.

[5] G.W. Qin, K. Oikawaa, G.D.W. Smithb, S.M. Hao, "Wire electric discharge machining induced titanium hydride in $\mathrm{Ti}-46 \mathrm{Al}-2 \mathrm{Cr}$ alloy", Intermetallics 11 (2003), pp 907-910. 
[6] Norliana Mohd Abbas, Darius G. Solomon, Md. Fuad Bahari, "A review on current research trends in electrical discharge machining (EDM)",. Int. J. Machine Tools Manufac, 47 (2007), pp 1214-1228.

[7] C.J. Puertas. Luis, "A study on the machining parameters optimization of electrical discharge machining", J. Mater. Process. Technol. 143 (2003), pp 521-526.

[8] K.H. Ho, S.T. Newman, S. Rahimifard, R.D. Allen, "State of the art in wire electrical discharge machining (WEDM)", Int. J. Machine Tools Manufac, 44 (2004), pp 1247-1259.

[9] K.M. Tsai, P.J. Wang, "Semi-empirical model of surface finish on electrical discharge machining", Int. J. Machine Tools Manufac, 41 (2001), pp 1455-1477.

[10]A. Yahya, C.D. Manning, "Determination of material removal rate of an electro-discharge machine using dimensional analysis", Journal of Physics D: Applied Physics 37 (2004), pp 14671471.

[11] M.L. Jeswani, "Dimensional analysis of tool wear in electrical discharge machining", Wear 55 (1979), pp 153-161.

[12] Ko-Ta Chiang, Fu-Ping Chang, "Optimization of the WEDM process of particle-reinforced material with multiple performance characteristics using grey relational analysis", J. Mater. Processing Technol, Vol. 180, Issues 13 Publication year:1 December 2006, pp 96 101.

[13]T. A. El-Taweel, "Parametric study and optimization of wire electrical discharge machining of $\mathrm{Al}-\mathrm{Cu}-\mathrm{TiC}-\mathrm{Si} \mathrm{P} / \mathrm{M}$ composite, Int. J. Machining and Machinability of Materials (IJMMM), Vol. 1, No. 4, (2006), pp 380-395.

[14] S. Sharif, R.M. Noordin, "Machinability modeling in powder mixed dielectric EDM of titanium alloy Ti-6246", Proceedings of the First International Conference and Seventh AUN/SEED-Net Fieldwise Seminar on Manufacturing and Material Processing, Kuala Lumpur, (2006), pp 133-138.

[15] M.S. Hewidy, T.A. El-Taweel, and M.F. ElSafty "Modeling the machining parameters of wire electrical discharge machining of Inconel 601 using RSM", J Mater Process Technol 169 (2005), pp 328-336.

[16] T. Taweel, "Multi-response optimization of EDM with $\mathrm{Al}-\mathrm{Cu}-\mathrm{Si}-\mathrm{TiC} \mathrm{P} / \mathrm{M}$ composite electrode", Int J Adv Manuf Technol, 44 (2009), pp 100-113.
[17] Montgomery D.C, "Design and analysis of experiments", Wiley, New York, (2001).

[18] J. Antony, "Design of experiments for engineers and scientists", Linacre House, Jordan Hill, Oxford OX2 8DP, (2003).

[19]A.B. Puri, B. Bhattacharyya, "Modeling and analysis of white layer depth in a wire-cut EDM process through response surface methodology", Int J Adv Manuf Technol, 25 (2005), pp 301307.

[20] K.T. Chiang, F.P. Chang, D.C. Tsai, "Modeling and analysis of the resolidified layer of SG cast iron in the EDM process through response surface methodology", J. Mater. Processing Technol,182: (2007), pp 525-533.

[21]N. Kinoshita, M. Fukui, H. Shichida, G. Gamo. "Study on EDM with wire electrode; Gap Phenomena", Annals of CIRP 25/1, (1976).

[22] M.T. Yan, Pin, "Accuracy improvement of wireEDM by real time wire tension control", Int. J. Machine Tools Manufac, (2004), pp 807-814.

[23] Y.F. Luo. "Rupture failure and mechanical strength of the electrode wire used in wire EDM.", J. Mater. Processing Technol, 94 (1999), pp 208-215.

[24]T.A. Spedding, Z.O. Wang. "Parametric optimization and surface characterization of wire electrical discharge machining process", Precision Engineering, 20 (1997), pp 5-15.

[25] Y.S. Liao, J.T., Huang, H.C. Sv, "A study on the machining parameters optimization of wire electrical discharge machining", J. Mater. Processing Technol, 71 (1997), pp 487-493.

[26] K. Kanlayasiri, S. Boonumung, "An investigation on effects of wire EDM machining parameters on surface roughness of newly developed DC 53 die steel", J. Mater. Processing Technol, 187-188 (2007), pp 26-29.

[27] M.I. Gokler, A.M. Ozanozgu, "Experimental investigation of effects of cutting parameters on surface roughness in WEDM process", Int. J. Machine Tools Manufac, 40 (2000), pp 18311848.

[28]G. Derringer, R. Suich, "Simultaneous optimization of several response variables",. Journal of Quality Techan,12, (1980), pp 214219.

[29]E.D. Castillo, D.C. Montgomery, D.R McCarville, "Modified desirability functions for multiple response optimization", Journal of Quality Technl, 28, (1996), pp 337-345. 